\title{
Women in Hybrid Roles in IT Employment: A Return to 'Nimble Fingers'?
}

\author{
Judith Glover, Yvonne Guerrier ${ }^{\prime}$
}

\begin{abstract}
Two key aspects of the Information Technology sector are the focus on clients and the 'new' organisational forms of teamwork and management by project. Both require employees who are able to combine technical and communication skills in the form of 'hybrid' jobs. We discuss the gendered development of hybrid jobs in the IT sector, proposing two overarching types of hybridity: inward-facing, tending to be done by women; and outward-facing, tending to be done by men. The 'boundaryless' career model, argued to be the model for successful careers in the IT sector, may link more to the outward-facing type. The gendered differentiation of hybrid jobs could therefore be one reason for women's segregation in IT employment and the attendant gender pay gap.
\end{abstract}

Keywords: women in IT employment; hybrid jobs; gendered hybrid jobs; boundaryless career.

\footnotetext{
I School of Business and Social Sciences, Roehampton University, 80 Roehampton Lane, London SWI5 5SL, UK. Email: j.glover@roehampton.ac.uk,y.guerrier@roehampton.ac.uk
} 


\section{Introduction: The Need for Social and Interactive Skills in IT}

The global IT sector is changing in key ways that affect the employment of IT professionals. The first way is what Loogma et al (2004: 323) refer to as a 'new service sector'. Darr (2002) argues that there has been a 'technicization' of the IT sector, with a growth in the demand for technical experts in the sales sector and a consequent reliance on social and interactive skills, since these technical experts are increasingly dependent on contextual knowledge held by the client. A number of new occupational roles have therefore emerged: in consultancy, client services and project management (Woodfield, 2002). Customer expectations are a key to product development in IT and IT firms are therefore have to interact closely with customers, observing keenly how they use the firm's products (Ruiz Ben, 2007). Ruiz Ben also points out that negotiations have to be conducted between different IT actors, both internal and external to the organisation, about standardization of quality.

The second key change relates to new organizational forms. There have been deep-seated changes in the way that knowledge-intensive firms are organised, with work primarily taking place in multi-functional and multi-skilled project teams (Alvesson, 1995). As the IT sector has transformed itself through outsourcing and off-shoring, these are increasingly multi-site teams. In this postbureaucratic model (Clegg, 1990), teamwork is the key organizational form. Teams need to be managed and held together. This requirement has been further strengthened in the IT sector by the advent of methods of working such as 'agile computing' which puts great emphasis on interand intra-team communication (Abrahamsson et al, 2002).

Increasingly, therefore, work in the IT sector, whether client-facing or team-facing, or a combination of the two, is seen as requiring a mix of technical and communication skills, in the form of what has become known in the academic literature (but generally not in the practitioner literature) as 'hybrid' jobs.

This article focuses on the gendering of these jobs and it is therefore appropriate to cover briefly the current situation of women's employment in IT. Our focus is on the UK, but a similar situation can be found in many other industrialized countries.

\section{Women's Representation in IT Employment in the UK}

The representation of women in IT employment remains low, although this was not always the case. When the development and use of Information Technology was in its infancy in the middle of the 20th century, the representation of women was relatively high (Webster, 1996). Women were primarily employed in programming and data entry tasks that required keyboard skills, much in line with the traditional employment of women in office work, where women's 'nimble fingers ' (Elson and Pearson, 198I) were assumed as 'natural' skills. These tasks became associated with men once it was recognized at the involved logic, electrical circuits and machines. New job titles developed, associated with the programming roles. Last programming and operator work became segregated from each other, with women concentrated in the operator roles (Webster, 1996). In the 1980s, changes in the nature of skilled roles in the IT sector were predicted to increase opportunities for women (Deakin, 1984). There were optimistic narratives about how the industry might transform itself, partly due to changing organisational structures, such as flatter hierarchies which it was thought might bring about an increase in women's employment (Edwards and Wajcman, 2005). However, recent research into small knowledge intensive firms in the IT sector suggests that the lack of organizational structure inherent in flat hierarchies allows for an unregulated culture that acts against many women's interests (Chassério and Légault, 2008; Greco, 2005).

Women's representation in the IT sector remains low in the UK and even shows a small decrease over the last 10 years. In the Standard Industrial Classification 'computing and related' category, women accounted for $25 \%$ of the workforce in 1997 and in 2008 the figure was $23 \%$. Full details are given in Table $\mathrm{Al}$ in a technical annex to this paper. There is furthermore evidence of a particularly low representation of women in the Standard Occupational Classification's skilled development roles, such as software engineer and strategy and planning professional. Table A2 in the technical annex gives full details. One result of this vertical segregation is a marked gender pay gap: the hourly full-time median pay of women in the 'computing and related' sector is $79 \%$ of that of men, i.e. a gender pay gap of $21 \%$ (authors' calculation from the Annual Survey of Hours and Earnings, 2009, www.statistics.gov.uk). This 
compares with a gender pay gap for the whole of the UK labour force of $12 \%$ (www.statistics.gov.uk).

The retention of those women who have entered professional IT jobs also appears to be an issue, particularly in the middle-career stage (DTI, 2005; Griffiths et al, 2007; Herman and Webster, 2007). Very recent evidence from the United States also indicates a similar issue (Simard and Gilmartin, 2010).

These figures show that women's low representation in the IT sector is not going away. A very large number of initiatives have been set up to try to redress this issue in Europe and globally (Domsch, 2006). The final report of a European Social Fund project lists over 50 initiatives in the UK alone to encourage women into IT, or to increase their retention and their return (Griffiths and Moore, 2006). These include a range of European Union funded projects, as well as UK government sponsored initiatives. In addition, women's networks and women's divisions of professional associations have been established, as well as private and public sector initiatives aimed at supporting women to enter or to return to IT. These are primarily of a liberal feminist nature and their effectiveness has been questioned (Vehviläinen and Brunila, 2007). It is difficult to assess their effectiveness, since little over-time evaluation appears to have been carried out (Domsch, 2006).

Jubas and Butterwick (2008:523) suggest that women deliberately try to move out of core IT areas into more feminised 'peripheral, feminised niches' such as website design, project management or technical writing. This raises the issue of what it is about the IT employment sector that could make women do this. Explanations about the structure and culture of the IT sector are relevant for our argument in this paper, particularly those which relate to what is known as the 'domestic division of labour'. Whilst some changes can be seen in terms of women's and men's roles in the household, there remains a cultural assumption that women are primarily responsible for the bulk of tasks, particularly those relating to the care of others (Sullivan 2004). An unequal domestic division of labour means that many employed women are disproportionately affected by the commonly found conditions of some aspects of IT employment, viz a long hours culture, a need to demonstrate commitment to remaining up-to-date with the technology despite gaps in employment, and a requirement for regular travel, with many roles, specifically the client-facing ones, requiring the employee to live nomadically (DTI, 2005; Fitzsimmons, 2002; Griffiths et al, 2007; Guerrier et al, 2009; Loogma et al, 2004).

There is evidence of a growing academic interest in examining what sort of jobs are done by women in the IT sector. Such work has the potential to provide alternative or complementary explanations of women's position in IT employment. There is also evidence of growing practitioner interest (for example Evans et al, 2007; Anita Borg Institute for Women and Technology, 2009). This developing work focuses on understanding the types of employment that women and men are concentrated in. This may have the potential to provide a new explanation of horizontal and vertical segregation amongst women and men in professional IT employment, as well as the gender pay gap.

\section{Hybrid Jobs}

Scott-Dixon (2005) makes the point that hybridity operates at two levels: firstly in terms of the work process, referring to different tasks and skills, and secondly in terms of work arrangements, such as hours, allocation and manner of work. Here we are referring to the first of these meanings, but Scott-Dixon's point is well made: the term lacks precision and has a tendency to be used to cover quite different issues. However there is probably agreement that they encompass both technical skills and 'soft' 2 skills such as creative, business, marketing and interpersonal. In the IT context, Woodfield (2000) describes the hybrid worker as the 'corporate ideal': someone who combines technical, interpersonal and organisational skills. Nevertheless, Whitehouse and Diamond (2005) and Simard and Gilmartin, (2010) make the point that a high status 'technical only' core is left intact, primarily done by men.

Hybrid jobs are varied and difficult to characterise (Ruiz Ben, 2007), but researchers generally agree that there are patterns of gender segregation: technically qualified women tend to be located in the less technical areas

\footnotetext{
${ }^{2}$ Although we continue to refer to 'soft' skills as such, we recognise that the term reinforces a perception of such skills as somehow inferior to 'hard' technical skills. As Jubas and Butterwick (2008: 52I) say:

The use of the words hard and soft is insidious... as the former term implies skills that are solidly entrenched and evident, while the latter implies a lack of definition and reliability.
} 
that are constructed as requiring the sorts of 'soft' skills that women 'naturally' have (Fitzsimmons, 2002; Griffiths et al, 2007; Guerrier et al, 2009; Kelan, 2008; Wajcman, 2004; Whitehouse and Diamond, 2005). The most prestigious and best paid roles in the IT sector require someone who can combine advanced technical skills with 'soft' management skills in so-called 'hybrid' positions and a number of studies show that it is men who tend to do this work (Fitzsimmons 2002; Trauth, 2002; Woodfield, 2002).

Employers in large IT companies unproblematically saw women's work in traditional domesticity-related terms, showing no evidence of a questioning of 'natural' skills, nor of any consciousness that these might limit the prospects of these highly qualified women (Guerrier et al, 2009). Hybrid jobs were often viewed as new opportunities for women, but the authors queried whether women were necessarily gaining from the hybrid jobs that employers viewed as new - and good - opportunities for women. Women may have been welcomed by employers more in terms of their presumed ability to change team dynamics than their technical ability. An unproblematic essentialism was detected: women were presented as a homogenous group compared with a homogenous group of men and differences between these groups ascribed as essential and biological. Particular sorts of tasks were regarded by employers as socially oriented - typically project and quality management - and women were seen as good at these. 'Technical but not very' was the way that one employer described a hybrid role. As the following quote shows, this employer chose to talk about women in hybrid roles being located in support roles. There is not therefore the suggestion that such roles are senior ones.

'I think we are seeing more and more women at the support end of the IT market so again because it's business facing.. it's technical but not very, you can choose how technical you want to get...again it comes down more to softer skills, personality, presentation, communication skills.' (cited in Guerrier et al, 2009)

This is very similar to the evidence quoted in Whitehouse and Diamond (2005) where a manager described the kinds of jobs that were more likely to be done by women:

They keep the operational wheels turning... It's a little bit tech, but not really tech. It's sort of operational. So yes, more females there... You know they've got families, they've got houses, they've got commitments.' (Whitehouse and Diamond, 2005: 85)

There is an easy slippage here between the cultural assumption that women are responsible for domestic issues, and that they prioritise them over paid work. They are there to keep the wheels turning. Fitzsimmons' (2002) description of support work shows it involving the type of emotional labour that has been well described in other types of customer service role (Hochschild, 1983), that of defusing customer anger, being patient and empathetic.

Guerrier et al (2009) argue further that hybrid opportunities might be good opportunities for men, because they were assumed not to be 'naturally' endowed with soft skills. Therefore, it would be an exceptional man who had them, and this should be rewarded. We suggested therefore, that moving away from purely technical roles to hybrid ones might be good for men, but less so for women. If a counterintuitive combination appears - a man who incorporates soft skills into his work - then something that could be negative for women could be positive for men. It may be an advantage for men in otherwise 'masculine' roles within a 'masculine' environment, to co-opt a version of femininity to demonstrate that they are empathetic (Adkins, 200I; Kelan, 2008). Men who are able to perform and appropriate traits associated with women, such as empathy, are especially valued:

'where performances of emotionality and aesthetics by women are so naturalised that they cannot cash them in as a resource in the career stakes.' (Wolkowitz, 2006: 94).

Further, Peterson (2007), looking at IT workers in Sweden, showed how women were more vulnerable to redundancy because they were perceived as having fewer 'tough' technical skills that provided a safe career path.

Guerrier et al (2009) found that 'soft' skills were not formally recognised in job descriptions. Whitehouse and Diamond (2005) similarly found that whilst there was general enthusiasm amongst managers for jobs that involved softer skills, there was recognition by these managers that cultural factors would mitigate against such jobs being valued. They conclude that there may be a

ISSN: 07I 8-2724. (http://www.jotmi.org)

Journal of Technology Management \& Innovation (C) Universidad Alberto Hurtado, Facultad de Economía y Negocios 
'cultural core' in IT organizations that devalue the status of some hybrid jobs (Whitehouse and Diamond, 2005: 87). Furthermore, Whitehouse and Diamond suggest that hybrid jobs will leave intact a core of high status IT work (for example design) since hybrid jobs will tend to be those that can easily be detached from this core. The use of a term 'core' implies of course the existence of a 'periphery', in which lower status roles may be located. Taking Whitehouse and Diamond's three indicative hybrid roles, a core/periphery continuum could be conceptualised. At one pole would be the consultant role, at the other the technical writer, and the software project managers at some point between the two. It is consistent with Whitehouse and Diamond's empirical results that one pole of the continuum also represents high pay and a concentration of men, whilst at the other there was low pay and a concentration of women.

The possibility is therefore raised that different types of hybrid roles carry different status. If hybridization means confirming essentialist ideas about women, then it is unlikely to be to their advantage. For it to be so, it would have to be built formally into job descriptions and have a reward structure. Women may be attractive to employers because of assumptions about their 'natural' caring skills; these match particularly to the skills required in inward-facing teambuilding hybrid roles. But if these roles are not being recognised in terms of career capital and remuneration, precisely because these skills are regarded as 'natural' and not therefore requiring formal training, then women are likely to be at a disadvantage. There is nothing new about this: from the Industrial Revolution in the West to more current Third World employment, employers have made assumptions that women naturally had 'nimble fingers' and such jobs were classified as low-skilled and correspondingly low paid (Elson and Pearson, 198I).

\section{Types of Hybrid Jobs in the Professional IT Sector}

Much existing work uses the hybrid term in a generic way, but hybrid jobs need to be differentiated. Without focusing on gender and focusing particularly on job identity, Loogma et al (2004) propose five different types, on the basis of interviews with both managers and employees. These embody differing amounts of technical and 'soft' skills: the geek, who identifies strongly with technology and is reluctant to develop broader communication skills; the techie, similar to the geek in terms of primary identification with the technical, but with more advanced communication skills; the flexible specialist, combining technical skills and having the ability to empathise with clients, representing the most desirable kind of employee and typically working as nomadic consultants; the translator, typically in a project management role, and liaising between the organization's computer experts (the geeks and techies) and clients; and finally the transgressor, who has largely moved away from the technical into management. Loogma et al go far, therefore, in identifying hybrid types that both employers and employees find meaningul, and their work focuses more than that of the other authors mentioned above on employees' work identities.

Loogma et al do not consider that their types might be gendered, in the sense that some may be done more by men than by women, although there is a hint that the translator is a role where women are concentrated. However, in their research into the gendering of computing jobs in Australia, Whitehouse and Diamond (2005) sought to identify women's and men's presence in three hybrid roles: consultants, required to combine technical and business expertise in the delivery of individualised systems to clients; software project managers, required to have a detailed knowledge of developing technologies and user needs, as well as overseeing projects and managing staff; technical writers, required to present technical information in a manner accessible to end users. These three jobs represented a hierarchy based on pay, with the consultants being best paid and the technical writers least.

Whitehouse and Diamond's findings, based on large scale organizational data, show that the highly paid consultant role was predominantly held by men, and that at the lower less well paid grades within that category, women's representation rose. In the second group, software project managers, women were markedly under-represented, but their representation was higher than in the consultancy group, and again, women were better represented in the lower paid roles within that category. By contrast, the lower paid technical writing category was heavily feminised, again particularly at the lower paid roles within that category.

Similarly in the spirit of seeking to identify different types of hybridity, we suggest on the basis on our previous work (Guerrier et al, 2009), that employers were implicitly (and 
not at all explicitly) seeing hybrid roles as being of two broad types: 'inward facing' and 'outward facing'. As well as requiring technical expertise, inward-facing jobs require skills of project management, team-building and empathy with other employees. These skills could be seen as the 'gel in the team'3. It seems a reasonable hypothesis, given the suppositions in the existing literature, that inwardfacing hybrid jobs are held mainly by women. Outward client-facing jobs, more likely to be held by men, and typically being in consultancy, require technical expertise as well as skills of communication and empathy with clients and the ability to be geographically mobile, since clients may demand the on-site presence of consultants. It is an empirical question, ripe for future research, whether a) these two broad types are meaningful to practitioners and b) the extent to which different types of hybrid roles are gendered, both from the perspective of employees' identities and that of organizational constructions.

\section{Hybrid Jobs and the Boundaryless Career}

Loogma et al (2004) introduce an element that may provide a further reason for the outward-facing hybrid role being advantageous to career advancement in the IT sector and the inward- facing one less so. The way to achieve advancement in the knowledge economy, they assert, is to adopt the boundaryless career model. The concept of the boundaryless career (Arthur and Rousseau, 1989) has received considerable attention in the sociology of employment and in organizational research. There is debate about the original model, but probably there is agreement that professional identity is now more important in career terms than organizational identity (Baruch and Cohen, 2007). The boundaryless career model has links with Lash's (2003) concept of 'insourcing': the individual, rather than the organization, is expected to take charge of his/her functions, activities and responsibilities. In this model, the professional self is innovative and autonomous; as an 'overriding self expected to bear the brunt of producing new knowledge, as well as creating new relationships of commitment and trust in an ever-changing and increasingly complex society" (Nerland and Jensen, 2007: 339).

The boundaryless career, say Loogma et al, involves ambiguity, uncertainty, a need for flexible behaviour and

\footnotetext{
${ }^{3}$ The expression 'gel in the team' was used by a presenter at a meeting in 2009 of the Women's Engineering Society in London, in arguing why the presence of women was necessary in otherwise all-male teams.
}

mobility. The employees in the Loogma et al study defined flexibility variously as being adaptable, responding to unpredictable situations and being willing to work long hours. Mobility was also interpreted variously: geographical as well as horizontal and vertical moves between jobs and employers. Sullivan and Arthur, in a refinement of the original boundaryless model definition, remind us that mobility can be both geographical and psychological (Sullivan and Arthur, 2006).

How does this relate to our previous discussion of different types of hybrid job, where we developed the binary of inward- and outward-facing? Our argument is that by its nature, the outward-facing hybrid role has more potential to acquire, and indeed the necessity to have, the kind of mobility, flexibility, networks and contacts that the boundaryless career requires. Thus, those doing this kind of role can acquire the social and cultural capital that allows them to move on and around, in a series of horizontal or vertical moves within the IT sector. Those doing internal-facing hybrid roles - and we have postulated that these are more likely to be women than men - have less opportunity to accumulate this sort of capital. This is because of the nature of their jobs, which in turn depends on the domestic commitments that many confront: the unequal domestic division of labour which we described in an earlier section of this paper.

Thus those in internal-facing hybrid roles may be operating in a more traditional bureaucratic model rather than the post-bureaucratic model in which the boundaryless career is located. Going back to Althauser and Kalleberg's (198I) conceptualisation of organizational and occupational careers, people in internal-facing hybrid roles are more likely to have organizational careers, whilst those doing external-facing hybrid roles have the potential to develop occupational careers, where skills are portable and transferable between organizations. This has much in common with the boundaryless career model. Loogma et al (2004: 336-7) even go so far as to say that this model of flexibility and geographical mobility suits the model of a young, independent person, whereas it becomes 'incompatible' for women who have to set it against 'more family oriented priorities'. They cite examples from their research of German and British employees in this situation who have left highly paid positions that demanded flexibility and mobility to take up lower paid positions with fewer of these demands 


\section{Discussion and Conclusion: 'Nimble Fingers'}

We have suggested that both require hybrid technical/'soft' skills, but that hybrid jobs are likely to be gendered. Men with 'soft' skills may be located in the client-facing external hybrid roles, and women in the internal teamwork roles. The external facing type is likely to be of higher status than the internal facing type and appropriately rewarded. This is because it is likely to be formally recognised by employers, since there may be the implicit assumption that the 'soft' skill part of the external facing job does not come 'naturally', and is therefore rare. Therefore status and remuneration are likely to follow. Furthermore, we have suggested that the characteristics of the external facing type are more in line with the boundaryless career model than those of the internal facing type. If the boundaryless career is the model that gives advancement in the IT sector, as Loogma et al suggest, then those with experience of external facing hybrid jobs stand a better chance in career terms. External facing hybrid jobs will give them access to the networks and industry-wide opportunities that the boundaryless career requires.

On the other hand, we hypothesise that the internal facing type is likely to be of lower status. This is because, although apparently highly valued by the organization (as Guerrier et al 2009 found from their interviews with employers) it is unlikely to be formally recognised, since the 'soft' skill part is assumed to come 'naturally'. Furthermore, the internal facing type may be more organizational than occupational (Althauser and Kalleberg, 198I), based on the perhaps outdated bureaucratic model of advancement within organizations. This may not give the networking possibilities required for the boundaryless career. Being the 'gel in the team' may be of great use to organizations, but such a role is unlikely to give the necessary social and cultural capital required for a boundaryless career and may, as Peterson (2007) found, make women vulnerable to redundancy. In a difficult financial climate this is obviously a pertinent issue. ${ }^{4}$

\footnotetext{
${ }^{4}$ In the run-up to the 2010 general election in the UK, the
Conservative party (the likely winners) are planning to meet the

${ }^{4}$ In the run-up to the 2010 general election in the UK, the
Conservative party (the likely winners) are planning to meet the massive budget deficit in part by cancelling IT projects in the public sector. It is possible that this will disproportionately affect women's jobs in IT.
}

ISSN: 07I 8-2724. (http://www.jotmi.org)

Journal of Technology Management \& Innovation (C) Universidad Alberto Hurtado, Facultad de Economía y Negocios
What we are suggesting, therefore, is that the advent of gendered hybrid roles, one of which may be valued above the other may be one explanation for gender segregation in IT employment and the attendant gender pay gap.

The foregoing discussion suggests parallels with the 'nimble fingers' thesis? Is the modern equivalent of 'nimble fingers' the 'gel in the team' argument? Our argument suggests that, in common with 'nimble fingers', the 'gel in the team' assumption attracts little in the way of formal recognition and therefore potential for advancement.

The domestic division of labour underpins the gendering of hybrid roles in two ways. First, the pervasive cultural imperative that women, and not men, are responsible for domestic and caring commitments restricts in practical ways the sorts of jobs that many women do. Second, the taken-for-grantedness of the domestic division of labour and women's 'natural' abilities, whether having 'nimble fingers' or being the 'gel', permeates the way that both employers and employees see women's skills; their 'naturalness' goes unquestioned.

As we noted at the beginning of this article, there are two major changes in the IT sector: the prevalence of its 'service sector' nature because of the key importance of relations with clients; and the management by project and teamwork. On the basis of the outward facing/inward facing binary that we have suggested, is it going too far to say that men in hybrid jobs may be meeting the first of these two changes, and women the second? Both are necessary, but each may be differentially rewarded.

\section{References}

ABRAHAMSSON, P., Salo, U.. Ronkainen, J. (2002). Agile Software Development Methods: Review and Analysis, Espoo: VTT Publications 478.

ADKINS, L. (200I). Cultural Feminization: "Money, Sex and Power" for Women. Journal of Women in Culture and Society 26 (3), 669-686.

ALTHAUSER, R., Kalleberg, A (198I). Firms, occupations and the structure of labor markets. Academic Press, New York.

ALVESSON, M (1995). Management of knowledge-intensive companies. De Gruyter, Berlin. 
ANITA BORG INSTITUTE FOR WOMEN AND TECHNOLOGY (2009). The Recruitment, Retention, and Advancement of Technical Women. Anita Borg Institute, California.

ARTHUR, M., Rousseau, D (1996). The Boundaryless Career. OUP, Oxford.

BARUCH, Y., Cohen, A (2007). The Dynamics between Organisational Commitment and Professional Identity Formation at Work, Identitites at Work In: A. Brown, S. Kirpal, Rauner, F. (eds) Springer, Dordrecht, 24I-60.

CLEGG, S (1990). Modern Organizations. Sage, London.

CHASSÉRIO, S., Légault, M-J. (2008). New organizational forms and persistence of gender gaps in high-tech firms. ICWES I 4, Lille, July.

DARR, A. (2002). 'The Technicization of Sales Work: an Ethnographic Study in the US Electronics Industry'. Work, Employment and Society, I6(I), 47-60

DEAKIN, R. (1984). Women and Computing: The Golden Opportunity. Macmillan, London.

DOMSCH, M. (2006). Quality Management in Gender and Diversity. Women in Science and Technology - the Business Perspective. DG Research Commission, Brussels.

DTI (2002). Maximising Returns to Science, Engineering and Technology Careers. DTI, London.

DTI (2005). Towards a Business Case for Diversity. DTI, London.

EDWARDS, P., Wajcman, J. (2005). The Politics of Working Life. Oxford University Press, Oxford.

ELSON, D., Pearson, R. (198I). Nimble Fingers Make Cheap Workers: An analysis of women's employment in Third World manufacturing exports. Feminist Review, Pp. 87-107.

EVANS, C., Glover, J., Guerrier, Y., Wilson, C. (2007). Effective Recruitment Strategies and Practices: Addressing Skills Needs and Gender Diversity in the ITEC and Related Sector. DTI, London.

FITZSIMMONS, A. (2002). Gender as a Verb. Ashgate, Hull.

GUERRIER, Y., Evans, C., Glover, J., Wilson, C (2009). "Technical, but not very....." Constructing gendered identities in IT-related employment. Work, Employment and Society, 23(3), 494-5II
GRECO, L (2005). 'Knowledge-intensive organisations: women's promised land? The case of the Irish software companies', Irish Journal of Sociology, I4(I), 45-65

GRIFFITHS, M., Moore, K., Richardson, H. (2007). Celebrating Heterogeneity?: A survey of female ICT professionals in England, Information, Communication and Society 10 (3), 338-357.

HERMAN, C., Webster, J. (2007). Editorial Comment. Information, Communication and Society - Special issue: 'Gender and IT', I0(3), 279-286.

HOCHSCHILD, A. (1983). The Managed Heart: Commercialization of Human Feeling. University of California Press, Berkeley.

JUBAS, K., Butterwick, S (2008). Hard/soft, formal/ informal, work/learning., J of Workplace Learning, 20(7/8), $5 \mid 4-25$

KELAN, E. K. (2008). Emotions in a Rational Profession: the Gendering of Skills in ICT Work. Gender, Work and Organization, I5(I), 49-7I.

LASH, S. (2003). Reflexivity as non-linearity. Theory, Culture and Society, 20(2,) 49-57.

LOOGMA, K., Ümarik, M., Vilu, R. (2004), Identificationflexibility dilemma of IT specialists. Career Development International, 9(3), 323-48

NERLAND, M., JENSEN K. (2007). "The Construction of a New Professional Self: A Critical Reading of the Curricula for Nurses and Computer Engineers in Norway". In: A. Brown, S. Kirpal, F. Rauner, F Identities at Work.. Springer Dordrecht, 339-60.

PETERSON, H. (2007). Gendered Work Ideals in Swedish IT Firms: Valued and Not Valued Workers, Gender, Work and Organization I4 (4), 333-348.

RUIZ BEN, E. (2007). Defining Expertise in Software Development While Doing Gender, Gender, Work and Organization, I4(4), 3|2-32

SCOTT-DIXON, K. (2005). From Digital Binary to Analog Continuum: Measuring Gendered IT Labor, Frontiers, 26(I), 24-43

SIMARD, C., Gilmartin, S. (2010). Senior Technical Women: A Profile of Success. Anita Borg Institute for Women and Technology, California. 
SULLIVAN, O. (2004). Changing Gender Practices within the Household. Gender \& Society, I8(2), 207-222

SULLIVAN, S., Arthur, M. (2006). The Evolution of the Boundaryless Career Concept: Examining Physical and Psychological Mobility. J of Vocational Behavior, 69, 19-29

TRAUTH, E. (2002). Odd girl out: an individual differences perspective on women in the IT profession. Information Technology and People, I5(2), 98-II8.

VEHVILÄINEN, M., Brunila, K. (2007). Cartography of Gender Equality Projects in ICT: Liberal equality from the perspective of situated equality. Information, Communication and Society, 10(3), 384-403.

WAJCMAN, J. (2004). TechnoFeminism. Polity Press, Cambridge.

WEBSTER, J. (1996). Shaping Women's Work: Gender, Employment and Information Technology. Longman, London.

WHITEHOUSE, G., Diamond, C. (2005). "Hybrids" and the Gendering of Computing Jobs in Australia. Australian Journal of Information Systems, I2(2), 79-89

WOLKOWITZ, C. (2006). Bodies at work. Sage, London.

WOODFIELD, R. (2000). Women, Work and Computing. Cidge, Cambridge University Press, Cambridge.

WOODFIELD, R. (2002). Woman and information systems development: not just a pretty (inter)face? Information Technology and People, 15(2), I19-38

\section{About the Authors}

Judith Glover is Professor of Employment Studies, School of Business and Social Sciences, Roehampton University, UK. She has published widely on women's employment, with a particular focus on science, engineering and technology. She is author of Women and Scientific Employment, Macmillan, 2000 and co-author, with Gill Kirton (Queen Mary University of London), of Women, Employment and Organizations, Routledge, 2006.

Yvonne Guerrier is Professor of Organizational Studies, School of Business and Social Sciences, Roehampton University, UK. Her research interests include the gendering of work, customer service work and the links between work and leisure. She has published widely on the nature of work in the hospitality and tourism industry. 


\section{Annex}

Table AI. Women's and men's representation in Standard Industrial Classification category 72, 'computing and related', 1997, 2006 and 2008, full-time employees.

\begin{tabular}{|l|l|l|l|}
\hline & 1997 & 2006 & 2008 \\
\hline Women & 60,000 & 97,000 & 103,000 \\
\hline Men & 177,000 & 330,000 & 342,000 \\
\hline Total & 237,000 & 427,000 & 445,000 \\
\hline Women as \% of men & $25 \%$ & $23 \%$ & $23 \%$ \\
\hline
\end{tabular}

Source: 1997 (National Earnings Survey), 2006 and 2008 (Annual Survey of Hours and Earnings (ASHE), authors' calculations from published statistics, www.statistics.gov.uk.

Table A2. Women's and men's representation in 5 associate professional and professional IT categories, full-time employees, 2009

\begin{tabular}{|l|l|}
\hline Occupational category (SOC) & $\begin{array}{l}\text { Women's representation (\% of the total of } \\
\text { women and men) }\end{array}$ \\
\hline IT managers & $19 \%$ \\
\hline IT strategy/planning & $14 \%$ \\
\hline professionals & \\
\hline Software professionals & $13 \%$ \\
\hline IT operations technicians & $22 \%$ \\
\hline IT user support technicians & $25 \%$ \\
\hline
\end{tabular}

Source: Annual Survey of Hours and Earnings (ASHE), 2009, authors' calculations from published statistics, www.statistics.gov.uk. 